\title{
RETRATOS DA VIOLÊNCIA DOMÉSTICA CONTRA AS MULHERES NO ESTADO DO PARÁ
}

\author{
MARIA AMÉLIA FADUL BITAR \\ Doutora em Ciências da Educação pela Faculdade Interamericana de Ciências Sociais. Mestre em Enfermagem pela \\ Universidade do Pará - UFPA. Professora Adjunta Titular do curso de enfermagem da Universidade Federal do Pará - UFPA. \\ Coordenadora do projeto de pesquisa intitulado "Discurso narrado pela mídia paraense sobre a violência contra a mulher \\ paraense cometida por homens". \\ País: Brasil Estado: Pará Cidade: Belém \\ Email de contato: ameliafadul@hotmail.com ORCID: https://orcid.org/0000-0002-7063-7969
}

VERA LÚCIA DE AZEVEDO LIMA

Enfermeira, docente do magistério superior, associado II Faculdade de Enfermagem/ICS/UFPA, Docente permanente do PPGSP/IFCH e Docente permanente do PPGENF/ICS/UFPA e Membro do grupo de pesquisa EPOTENA.

País: Brasil Estado: Pará Cidade: Belém

Email de contato: veraluci@ufpa.br ORCID: http://orcid.org/0000-0003-0094-4530

\section{GESIANY MIRANDA FARIAS}

Possui graduação em Enfermagem pela Universidade Federal do Pará e mestrado em Enfermagem pela Universidade Federal do Pará pela linha de pesquisa políticas públicas de saúde no contexto amazônico.

País: Brasil Estado: Pará Cidade:Belém

Email de contato: gesiany.farias@hotmail.com ORCID: https://orcid.org/0000-0002-9442-7296

Contribuição de cada autora:

Todas as autoras contribuíram com a concepção do estudo, análise e interpretação dos dados, redação do artigo, revisão crítica relevante do conteúdo intelectual e aprovação da versão final a ser publicada.

\section{RESUMO}

O objetivo desta pesquisa foi analisar os dados estatísticos sobre a violência doméstica contra as mulheres no Estado do Pará no período de 2008 a 2015. O estudo foi desenvolvido com uma abordagem quantitativa referente ao tema, tendo como objeto analítico descritivo o fenômeno da violência doméstica contra a mulher. Os dados foram coletados do banco de dados do Sistema Integrado de Segurança Pública. Os resultados foram analisados através da estatística descritiva e apresentados em forma de tabelas e gráficos. De acordo com os dados quantitativos mostrados por este estudo, das 905.694 ocorrências registradas por crimes contra a mulher no Estado do Pará nos anos pesquisados, 31.793, ou seja, 3,5\% do total, foram enquadradas pela autoridade policial como violência doméstica de acordo com a Lei Maria da Penha. A média anual de denúncias foi de 3.974 casos. Desse modo, tornam-se essenciais ações de prevenção, assistência e políticas de garantia dos direitos da mulher por diversos setores envolvidos, tais como: saúde, educação, assistência social, segurança pública, cultura, justiça, entre outros; no sentido de dar conta da complexidade da violência contra as mulheres.

Palavras-chave: Direitos Humanos. Lei Maria da Penha. Violência doméstica. 


\section{ABSTRACT PORTRAYAL OF DOMESTIC VIOLENCE AGAINST WOMEN IN THE STATE OF PARÁ}

The objective of this research was to analyze the statistical data concerning domestic violence against women in the State of Pará in the period from 2008 to 2015. The study was developed with a quantitative approach regarding the theme, having as descriptive analytical object the phenomenon of domestic violence against women. The data were collected from the Integrated Public Security System Database. The results were analyzed using descriptive statistics and presented in the form of tables and graphs. According to the quantitative data shown by this study, of the 905,694 occurrences recorded for crimes against women in the State of Pará in the years surveyed, 31,793, in other words, 3.5\% of the total, was classified by the police as domestic violence according to the Maria da Penha Law. The annual average of complaints was 3,974 cases. Thereby, prevention, assistance and policies to guarantee women's rights are essential for various sectors involved, such as: health, education, social assistance, public security, culture, justice, among others; for the purpose of to reach the complexity of violence against women.

Keywords: Human Rights. Maria da Penha Law. Domestic Violence.

DOI: 10.31060/rbsp.2021.v15.n1.1177

Data de recebimento: 26/06/2019 - Data de aprovação: 10/07/2020

\section{INTRODUÇÃO}

De acordo com a Organização Mundial da Saúde (OMS), a violência contra a mulher é um problema de saúde pública (WHO, 2013), sendo uma violação dos direitos humanos básicos, se configurando em um grande dilema da humanidade em pleno século XXI (GRANJA; MEDRADO, 2009). Nesse âmbito, a violência contra a mulher traduzida na forma de violência doméstica é um grave desrespeito à dignidade da pessoa humana, uma vez que todas as formas de violências e comportamentos dominantes se caracterizam por relações assimétricas entre gêneros, referindo-se, portanto, às relações desiguais de poder, ocorrendo em todas as camadas sociais, sendo observável constantemente no cotidiano das mulheres, sob diferentes formas de representações ideológicas, classes sociais, raças e etnias (BARRETO, 2007).

Em 2015, a Central de Atendimento à Mulher, o Ligue 180, teve 76.651 relatos de violência contra mulheres no Brasil, mostrando que as ações de prevenção têm sido insuficientes (BRASIL, 2016). De outro lado, quanto às ações de enfrentamento, gravitam denúncias acerca da morosidade do julgamento dos processos e do baixo número de prisões. Esses dados apontam à necessidade de se trabalhar na prevenção e no enfrentamento da violência (SOUZA, 2016).

No combate à violência doméstica é inquestionável a importância da implementação da Lei nº 11.340/2006, conhecida como Lei Maria da Penha (LMP), no ordenamento jurídico pátrio, marco histórico na luta das mulheres no enfrentamento à desigualdade de gênero e da violência doméstica (BRASIL, 2006).

Entretanto, a legislação, embora necessária, não é suficiente para acabar com a violência doméstica ainda crescente no Brasil; a prevenção e o enfrentamento da violência contra a mulher passam necessariamente pela redução das desigualdades entre os gêneros e requerem políticas públicas eficazes, além do engajamento de diferentes setores da sociedade, para garantir que todas as mulheres e meninas tenham acesso ao direito básico de viver sem violência (MIRANDA et al., 2016). 
Desse modo, conhecer os perfis da violência contra a mulher registrados no Pará, pode contribuir para a criação ou a elaboração de políticas públicas setoriais para o enfrentamento da violência nessa região. Diante dessa perspectiva, este estudo foi conduzido pela seguinte questão norteadora: qual o panorama estatístico de violência doméstica contra a mulher no Estado do Pará nos anos de 2008 a 2015? Tendo como objetivo geral analisar os dados estatísticos sobre a violência doméstica contra a mulher no Estado do Pará no período de 2008 a 2015.

\section{METODOLOGIA}

O estudo foi desenvolvido com uma abordagem quantitativa referente ao tema, tendo como objeto analítico descritivo o fenômeno da violência doméstica contra a mulher. O lócus de pesquisa foi o Estado do Pará, localizado na Região Norte, com extensão territorial de 1.247.950.000 quilômetros quadrados. É a segunda maior Unidade Federativa do Brasil, correspondendo a 14,6\% do território nacional. Conforme a última contagem populacional realizada em 2010 pelo Instituto Brasileiro de Geografia e Estatística (IBGE), sua população é de 7.581.051 habitantes distribuídos em 144 municípios (IBGE, 2010).

Os dados foram coletados do banco de dados do Sistema Integrado de Segurança Pública SISP/WEB após autorização da Secretaria Adjunta de Inteligência e Análise Criminal. Esses dados expuseram o perfil das mulheres vítimas de violência doméstica (etnia, faixa etária, escolaridade, cor e profissão), o número de registros das mulheres vítimas de violência doméstica no Estado do Pará, os municípios das vítimas, o número de registros por tipificação criminal, o número de processos encaminhados à justiça e o crescimento linear da Violência Contra a Mulher (VCM). O período estudado compreende os anos de 2008 a 2015.

Os resultados foram analisados por meio de estatística descritiva e apresentados em forma de tabelas e gráficos. A estatística descritiva é considerada um conjunto de técnicas analíticas utilizada para resumir o conjunto dos dados recolhidos numa dada investigação organizados geralmente por números, tabelas e gráficos (MORAIS, 2015).

\section{RESULTADOS}

Apresentaremos a seguir os dados obtidos dos registros policiais de mulheres que fizeram notificação de violência doméstica no Estado do Pará nos anos de 2008 a 2015. Por intermédio desses dados foi possível identificar o número de ocorrências, os principais tipos e as características predominantes das mulheres vítimas de violência doméstica e familiar relacionadas à faixa etária, escolaridade, cor e profissão. A compreensão desses fatores está explícita nas tabelas e nos gráficos a seguir. Após a análise das informações estatísticas sociodemográficas apresentamos, conforme exibido no Gráfico 1, os dados da violência no Estado do Pará. 


\section{GRÁFICO 1}

Quantitativo de registro de crimes X crimes enquadrados na Lei Maria da Penha nos anos de 2008 a 2015

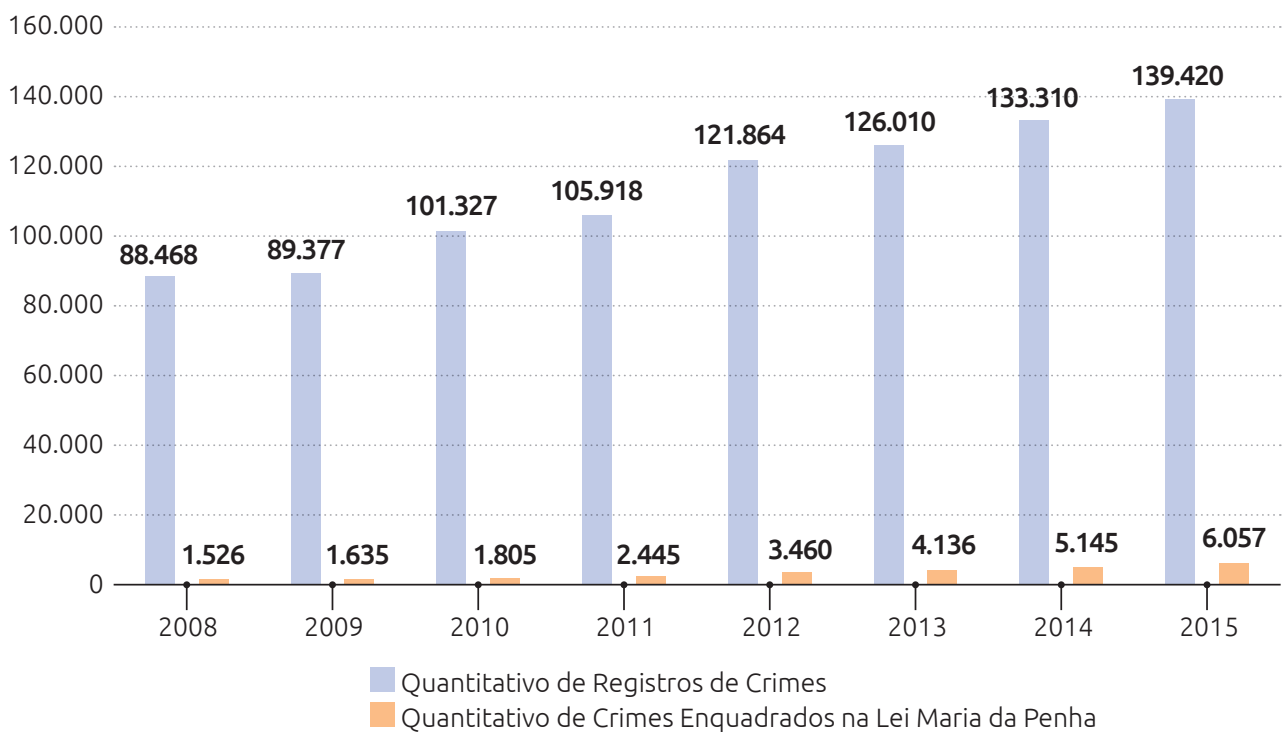

Fonte: SISP - Sistema Integrado de Segurança Pública; Secretaria Adjunta de Inteligência e Análise Criminal - SEGUP/PA.

Das 905.694 ocorrências registradas por crimes contra a mulher no Estado do Pará nos anos pesquisados (2008 a 2015), 31.793 (ou seja, 3,5\% do total) foram enquadradas pela autoridade policial de acordo com a Lei Maria da Penha. Conforme os dados obtidos no período de 2008 a 2015, verificou-se um total de 31.793 situações de violência contra mulheres. Se esse total fosse dividido por ano, seria encontrada uma média de 3.974 situações anuais de violência contra a mulher.

A violência doméstica é um grave problema social oriundo de desigualdades históricas promovidas pelo sistema patriarcal, que colocava a mulher em posição de subordinação, promovendo diferenças entre os papéis masculinos e femininos dentro da sociedade (SILVA, 2017). De acordo com o Painel de Violência contra as Mulheres do Senado Federal, em 2016, no Brasil, foram registrados 224.946 boletins de ocorrência de violência contra mulheres, ou seja, a cada 100 mil mulheres, 211,5 denunciaram os seus agressores (SENADO FEDERAL, 2016).

Apesar do aumento do número de mulheres que procuram as delegacias e prestam queixas, o quantitativo das que não denunciam o agressor ou das que procuram as delegacias, mas não registram a queixa, supera em muito os dados oficiais. Na Tabela 1 o número de mulheres paraenses que fizeram notificações de violência doméstica em todo o Estado do Pará no período de 2008 a 2015 foi de 3,5\% (31.793 mulheres) em relação à população feminina, de acordo com os dados do Censo 2010 (IBGE, 2010). 


\section{TABELA 1}

\begin{tabular}{|c|c|c|c|c|c|c|c|c|c|}
\hline \multicolumn{10}{|c|}{$\begin{array}{l}\text { Demonstrativo das vítimas de violência doméstica na Região Integração Guajará e demais regiões nos } \\
\text { anos de } 2008 \text { a } 2015\end{array}$} \\
\hline Município & 2008 & 2009 & 2010 & 2011 & 2012 & 2013 & 2014 & 2015 & Total Geral \\
\hline Belém & 287 & 842 & 918 & 1086 & 1106 & 1241 & 1365 & 1570 & 8415 \\
\hline Ananindeua & 132 & 217 & 248 & 367 & 541 & 522 & 574 & 660 & 3261 \\
\hline Marituba & 74 & 95 & 166 & 193 & 201 & 231 & 254 & 292 & 1506 \\
\hline Benevides & 19 & 44 & 43 & 63 & 63 & 84 & 92 & 106 & 514 \\
\hline Santa Bárbara & 6 & 9 & 13 & 13 & 22 & 19 & 21 & 24 & 127 \\
\hline Total R.I. Guajará & 518 & 1207 & 1388 & 1722 & 1933 & 2097 & 2306 & 2652 & 13823 \\
\hline Total demais R.I. & 687 & 1328 & 1713 & 2339 & 2674 & 2788 & 3067 & 3374 & 17970 \\
\hline Total Estado & 1205 & 2535 & 3101 & 4061 & 4607 & 4885 & 5373 & 6026 & 31793 \\
\hline
\end{tabular}

Fonte: SISP - Sistema Integrado de Segurança Pública; Secretaria Adjunta de Inteligência e Análise Criminal - SEGUP/PA.

Em relação aos dados apresentados na Tabela 1, das 31.793 notificações das vítimas de violência doméstica no período em estudo, a Região 7, ou Região de Integração Guajará, formada pelos municípios de Ananindeua, Belém, Benevides, Marituba e Santa Bárbara, registrou $13.823(43,4 \%)$ do total de notificações. Os resultados mostram um crescimento linear de denúncias no período compreendido de 2008 a 2015, onde se observa um crescimento médio de 512\% de violência contra mulheres que sofreram agressão e registraram boletim de ocorrência. Esses dados apontam a necessidade de ações para a redução da violência contra a mulher em nosso Estado.

Em termos de violência contra a mulher, na região metropolitana de Belém (PA), a cada uma hora registrase cerca de dois casos de violência contra a mulher. Em 2018, ainda nessa mesma localidade, foram 14 mil relatos de agressões contra mulheres. Em relação ao Estado do Pará, obtiveram-se 19 mil registros de agressões às mulheres, um acréscimo de 14\% em relação ao ano de 2017 (SÓTER; MAIA, 2019).

A região de maior prevalência de violência doméstica apontada na Tabela 1 é composta de municípios situados geograficamente próximos à capital, que cresceram de forma desordenada, com muitas áreas pobres, precárias em termos de saneamento básico, urbanização e desigualdades sociais (VILARINS, 2019).

De acordo com um estudo que mapeou os casos de violência contra a mulher na região metropolitana de Belém (PA), os maiores números de casos se concentram em Belém (52,2\%), seguida de Ananindeua $(31,7 \%)$ e Marituba (9,8\%). Nessas localidades, a ausência de segurança pública impede que os demais órgãos públicos exerçam seus trabalhos, como as instituições de apoio à mulher vítima de violência doméstica e até mesmo as Unidades Básicas de Saúde (UBS), que poderiam intervir a favor do controle dessa violência (AUGUSTO et al., 2015).

Esses achados corroboram a necessidade de desconcentrar os focos de estabelecimentos de enfrentamento da violência contra a mulher na capital para as diversas cidades que compõem a região metropolitana da capital, levando unidades de atendimentos principalmente para os interiores com maior índice desse fenômeno.

Por meio desta pesquisa, constatou-se a falta de registros importantes para o estabelecimento do perfil das mulheres vítimas de violência, dados esses significativos para as sistematizações quantitativa e qualitativa sobre a realidade da violência doméstica contra a mulher. 
Na Tabela 2, a seguir, pode ser visto o perfil das vítimas por faixa etária das mulheres que denunciaram a violência doméstica sofrida no Estado do Pará no período de 2008 a 2015. Cerca de 15.000 ocorrências não tiveram a idade da vítima registrada, apesar da importância desse dado, visto que a faixa etária é considerada um agravante em casos de violência.

\section{TABELA 2}

\begin{tabular}{|c|c|c|c|c|c|c|c|c|c|}
\hline \multicolumn{10}{|c|}{$\begin{array}{l}\text { Demonstrativo de perfil/faixa etária das vítimas de violência doméstica no Estado do Pará nos anos de } \\
2008 \text { a } 2015\end{array}$} \\
\hline Faixa Etária & 2008 & 2009 & 2010 & 2011 & 2012 & 2013 & 2014 & 2015 & Total Geral \\
\hline Sem Preenchimento & 548 & 1229 & 1537 & 1976 & 2162 & 2326 & 2391 & 2726 & 14895 \\
\hline Adolescentes (12 a 17 anos) & 56 & 127 & 144 & 195 & 228 & 262 & 375 & 389 & 1776 \\
\hline Adulto I (18 a 24 anos) & 166 & 319 & 395 & 520 & 653 & 602 & 673 & 695 & 4023 \\
\hline Adulto II (25 a 29 anos) & 127 & 260 & 344 & 535 & 503 & 510 & 615 & 691 & 3585 \\
\hline Adulto III (30 a 34 anos) & 109 & 207 & 267 & 317 & 390 & 442 & 493 & 586 & 2811 \\
\hline Adulto IV (35 a 64 anos) & 193 & 375 & 394 & 493 & 636 & 711 & 788 & 880 & 4470 \\
\hline Idoso (65 anos ou mais) & 6 & 18 & 20 & 25 & 35 & 32 & 38 & 59 & 233 \\
\hline Total Geral & 1205 & 2535 & 3101 & 4061 & 4607 & 4885 & 5373 & 6026 & 31793 \\
\hline
\end{tabular}

Fonte: SISP - Sistema Integrado de Segurança Pública; Secretaria Adjunta de Inteligência e Análise Criminal - SEGUP/PA.

Os resultados encontrados neste estudo mostram que as mulheres adultas jovens (de 18 a 34 anos) são as que mais sofreram violência doméstica, atingindo um percentual de 61,65\%, sendo que 14.895 (47 \% da amostra) não tiveram suas idades registradas. Um estudo realizado no Pará, com o objetivo de caracterizar as mulheres vítimas de agressão pelos seus (ex) parceiros atendidas no Instituto Médico Legal (IML), encontrou como faixa etária mais prevalente a de 18 a 29 anos, correspondendo a 53,12\% dos casos. Dados esses compatíveis com os encontrados neste trabalho (BOTELHO et al., 2012).

Um estudo da violência doméstica e familiar contra a mulher na cidade de Ponta Grossa (PR), realizado na

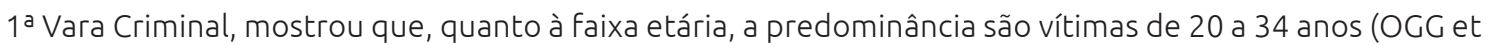
al., 2013). De acordo com estudos realizados em prontuários de mulheres vítimas de violência doméstica periciadas no IML de Cuiabá (MT), a média de idade das mulheres agredidas foi de 32,5 anos, sendo que $77,5 \%$ dessas vítimas encontravam-se na faixa etária de 18 a 39 anos, o que reitera os dados obtidos neste estudo (NOGUEIRA et al., 2017).

Para Bernardino et al. (2016) essa faixa etária é caracterizada, também, como um importante estágio do ciclo de vida da mulher, relacionado, para muitas, como um período reprodutivo, de atenção e cuidado com os filhos. Sinaliza-se que a maioria das vítimas de violência doméstica são mulheres adultas e jovens, proativas profissionalmente, fazendo com que a situação de violência vivenciada por elas interfira em sua capacidade laboral e na manutenção do seu emprego, provocando redução da sua produtividade, tendo como consequência o desemprego e os aumentos dos gastos previdenciários e da utilização do sistema de saúde.

Das 31.793 mulheres que fizeram registro de ocorrência de violência doméstica no Estado do Pará entre 2008 e 2015 apenas em 17.429 notificações (54,8\%) obteve-se o registro de escolaridade. O estudo aponta que prevaleceram as mulheres com ensino fundamental incompleto, correspondendo a $25 \%$, seguido de $11 \%$ de mulheres com ensino médio completo. O número de mulheres com nível superior completo foi de $2 \%$, como demonstrado na Tabela 3. 


\section{TABELA 3}

\begin{tabular}{|c|c|c|c|c|c|c|c|c|c|}
\hline \multicolumn{10}{|c|}{$\begin{array}{l}\text { Demonstrativo de perfil/escolaridade das vítimas de violência doméstica no Estado do Pará nos anos de } \\
2008 \text { a } 2015\end{array}$} \\
\hline Escolaridade & 2008 & 2009 & 2010 & 2011 & 2012 & 2013 & 2014 & 2015 & Total Geral \\
\hline Sem Preenchimento & 439 & 1023 & 1426 & 1896 & 2058 & 2260 & 2497 & 2742 & 14341 \\
\hline Desconhecido & 1 & 5 & 2 & 1 & 6 & 2 & 2 & 4 & 23 \\
\hline Não Alfabetizada & 19 & 34 & 29 & 35 & 47 & 60 & 63 & 69 & 356 \\
\hline $\begin{array}{l}\text { Ensino Fundamental } \\
\text { Incompleto }\end{array}$ & 364 & 701 & 765 & 968 & 1129 & 1172 & 1275 & 1463 & 7837 \\
\hline $\begin{array}{l}\text { Ensino Fundamental } \\
\text { Completo }\end{array}$ & 86 & 172 & 183 & 192 & 257 & 236 & 263 & 289 & 1678 \\
\hline Ensino Médio Incompleto & 111 & 217 & 261 & 336 & 402 & 406 & 447 & 502 & 2682 \\
\hline Ensino Médio Completo & 140 & 300 & 327 & 461 & 545 & 548 & 602 & 693 & 3616 \\
\hline $\begin{array}{l}\text { Ensino Superior } \\
\text { Incompleto }\end{array}$ & 16 & 37 & 52 & 87 & 84 & 97 & 106 & 125 & 604 \\
\hline Ensino Superior Completo & 29 & 46 & 56 & 85 & 79 & 104 & 118 & 139 & 656 \\
\hline Total Geral & 1205 & 2535 & 3101 & 4061 & 4607 & 4885 & 5373 & 6026 & 31793 \\
\hline
\end{tabular}

Fonte: SISP - Sistema Integrado de Segurança Pública; Secretaria Adjunta de Inteligência e Análise Criminal - SEGUP/PA.

Um estudo realizado em João Pessoa (PB), em relação ao grau de escolaridade das mulheres vítimas de violência, evidenciou 9 mulheres (33\%) com ensino fundamental completo, seguidas de 7 (26\%) com ensino médio incompleto. Apenas 4\% possuíam ensino superior completo e uma se declarou analfabeta (SILVA et al., 2013). Esses dados apresentam semelhança com os dados apresentados nesta pesquisa. Estudo realizado na cidade de Embu (SP), no ano de 2010, constatou que mais da metade da amostra de mulheres vítimas de violência $(413 ; 52,7 \%)$ não tinha completado o ensino fundamental, com média de $7,1 \pm 3,3$ anos de escolaridade (MIRANDA; PAULA; BORDIN, 2010).

Os achados do presente trabalho foram compatíveis com os resultados encontrados por Garcia et al. (2016), que analisaram variáveis relacionadas à violência doméstica no Brasil com base nos dados das vítimas de acidentes e violências coletados por meio de inquérito que compõe a Vigilância de Violências e Acidentes (VIVA), em 2011. Ficou evidente que as mulheres com menor escolaridade e que estão em situação de vulnerabilidade social e econômica são as que mais procuram os serviços institucionais em virtude da violência.

Tal situação é apontada por Vale et al. (2013) como um dos fatores que favorece a situação de violência, pois, quanto menor o suporte social e financeiro, maior o risco de violência. Mulheres com menor escolaridade geralmente estão em condições de pobreza, o que favorece a exclusão social e a baixa autoestima, reduzindo as perspectivas de que possam exercer atividades bem remuneradas no mercado de trabalho.

A instrução escolar facilita a inserção da mulher no mercado de trabalho, melhorando conjuntamente sua condição econômica e determinando também o maior acesso ao conhecimento, o que possibilita melhor compreensão dos direitos e deveres do cidadão, permitindo maior acesso à justiça, à saúde e até mesmo ao conhecimento de seus direitos (OGG et al., 2013).

Entretanto, mesmo com todas as conquistas dos movimentos feministas, as mulheres ainda não têm o mesmo valor no mercado de trabalho em comparação com os homens; elas ganham salários mais baixos e têm menos chances de ascensão profissional, mesmo quando possuem melhores qualificações (PEREIRA, 
2017). É importante lembrar que a violência doméstica atinge, também, as classes mais instruídas, porém, nessas circunstâncias a subnotificação dos casos é mais proeminente (ZART; SCORTEGAGNA, 2015).

Os resultados apresentados na Tabela 4 mostram a distribuição das mulheres que fizeram notificação de violência doméstica no Estado do Pará entre 2008 e 2015 por cor da pele, entretanto, é importante considerar que apenas 143 mulheres do total das que fizeram boletim de ocorrência tiveram esse item preenchido. Nos dados registrados houve predominância da cor preta, com 75,5\%, seguida da cor branca, com 22,4\%.

\section{TABELA 4}

\begin{tabular}{|c|c|c|c|c|c|c|c|c|c|}
\hline \multicolumn{10}{|c|}{$\begin{array}{l}\text { Demonstrativo de perfil/cor da pele das vítimas de violência doméstica no Estado do Pará nos anos de } \\
2008 \text { a } 2015\end{array}$} \\
\hline Cor da Pele & 2008 & 2009 & 2010 & 2011 & 2012 & 2013 & 2014 & 2015 & Total Geral \\
\hline Sem Preenchimento & 1200 & 2527 & 3087 & 4038 & 4591 & 4870 & 5348 & 5989 & 31650 \\
\hline Amarela & 0 & 0 & 0 & 0 & 0 & 1 & 1 & 1 & 3 \\
\hline Branca & 1 & 1 & 6 & 4 & 2 & 4 & 6 & 8 & 32 \\
\hline Preta & 4 & 7 & 8 & 19 & 14 & 10 & 18 & 28 & 108 \\
\hline Total Geral & 1205 & 2535 & 3101 & 4061 & 4607 & 4885 & 5373 & 6026 & 31793 \\
\hline
\end{tabular}

Fonte: SISP - Sistema Integrado de Segurança Pública; Secretaria Adjunta de Inteligência e Análise Criminal - SEGUP/PA.

Os números encontrados nesta pesquisa apontam que em nosso Estado as mulheres negras são as maiores vítimas de violência doméstica, o que coincide com os dados relacionados ao nosso país. O Brasil registrou, nos dez primeiros meses de 2015, 63.090 denúncias de violência contra mulheres, o que corresponde a 1 relato a cada 7 minutos no país. Entre esses registros, quase metade (31.432 ou 49,82\%) corresponde a denúncias de violência física e 58,55\% foram relatos de violência contra mulheres negras (BRASIL, 2015).

O Mapa da Violência 2015 mostra que o número de mortes violentas de mulheres negras aumentou 54\% em dez anos, passando de 1.864, em 2003, para 2.875, em 2013. No mesmo período, a quantidade anual de homicídios de mulheres brancas diminuiu 9,8\%, caindo de 1.747, em 2003, para 1.576, em 2013. Observa-se divergência nas representações sociais quando o Mapa da Violência aponta que a partir da Lei Maria da Penha o número de violências contra as mulheres brancas caiu 2,1\% e aumentou 35\% entre as mulheres negras, mostrando que estas mulheres são as que estão em maior situação de vulnerabilidade (WAISELFISZ, 2015).

Esses dados ressaltam a situação de vulnerabilidade em que se encontra esse grupo de mulheres, o que envolve espaços e oportunidades precários de trabalhos e baixos índices socioeconômicos e de escolaridade. O preconceito e a discriminação são evidenciados nos dados socioeconômicos que indicam que as mulheres, principalmente as negras, são discriminadas no mercado de trabalho, quando não conseguem empregos ou ocupam cargos secundários, mesmo quando qualificadas e instruídas, ou ainda quando recebem salários inferiores quando ocupam os mesmos cargos que os homens e as mulheres brancas (CACCIAMALI; HIRATA, 2005).

A violência contra a mulher é uma questão social e de saúde pública. Desse modo, torna-se essencial que se discuta a violência contra as mulheres não apenas numa perspectiva de gênero, mas também de raça, ou seja, buscar a interseccionalidade nessa discussão, compreendendo que a discriminação de gênero se intensifica na vida das mulheres negras, por isso o poder público deve promover políticas de enfrentamento às desigualdades sociais ocasionadas pela questão de gênero e do racismo, infelizmente ainda presente na sociedade (CEPAL, 2018). 
No que toca especificamente à violência doméstica e familiar, esta sequer é registrada em termos de tematizações raciais, tanto que, nos casos de denúncia nas Delegacias Especializadas de Atendimento à Mulher (DEAMs), o item "cor da pele" geralmente é inexistente ou não é preenchido nos formulários de identificação (ALMEIDA; PEREIRA, 2012).

Portanto, os dados agrupados na Tabela 4 acima devem ser olhados com bastante cautela, uma vez que a confiabilidade dos mesmos carece de ratificação, haja visto que na quase totalidade dos boletins de ocorrência, em 31.650 casos (99,6 \%), não foi preenchido o quesito cor da pele. Isso faz refletir sobre a falta de algumas informações dos boletins de ocorrências, os quais influenciam de forma direta na qualidade dos dados colhidos.

É importante lembrar que a falta de registro da cor da pele inicia-se no momento da realização do boletim de ocorrência, ou seja, pela possibilidade de tais informações não serem priorizadas pelos profissionais atuantes, ou pelo não reconhecimento de sua cor da pele por parte das mulheres, quando é solicitado pelo agente o preenchimento dos dados pessoais nos documentos. Esses dados geram estatísticas que fomentam políticas públicas efetivas de combate à violência contra a mulher no geral, dando visibilidade para as que são mais acometidas por essa violação de direitos, o que, em consequência, permite exigir maiores políticas públicas para contemplar essas mulheres.

\section{TABELA 5}

\section{Demonstrativo de perfil/profissão das vítimas de violência doméstica no Estado do Pará nos anos de} 2008 a 2015

\begin{tabular}{|c|c|c|c|c|c|c|c|c|c|}
\hline & 2008 & 2009 & 2010 & 2011 & 2012 & 2013 & 2014 & 2015 & Total Geral \\
\hline Sem Preenchimento & 557 & 1245 & 1661 & 2259 & 2390 & 2633 & 2886 & 3223 & 16854 \\
\hline $\begin{array}{l}\text { Profissional de Nível } \\
\text { Superior }\end{array}$ & 32 & 55 & 62 & 69 & 83 & 110 & 125 & 130 & 666 \\
\hline Agricultora & 4 & 20 & 22 & 32 & 20 & 29 & 31 & 37 & 195 \\
\hline Aposentada & 9 & 13 & 20 & 20 & 31 & 24 & 26 & 28 & 171 \\
\hline Auxiliar Geral & 13 & 26 & 47 & 54 & 64 & 58 & 64 & 71 & 397 \\
\hline Cabelereira & 6 & 18 & 16 & 18 & 29 & 26 & 28 & 31 & 172 \\
\hline Comerciante & 29 & 49 & 61 & 53 & 78 & 58 & 63 & 69 & 460 \\
\hline Comerciária & 3 & 9 & 12 & 21 & 19 & 25 & 27 & 29 & 145 \\
\hline Costureira & 7 & 9 & 12 & 16 & 18 & 18 & 19 & 21 & 120 \\
\hline Cozinheira & 4 & 10 & 14 & 24 & 25 & 28 & 31 & 35 & 171 \\
\hline Dona de Casa & 211 & 399 & 449 & 531 & 719 & 693 & 755 & 803 & 4560 \\
\hline Empregada Doméstica & 167 & 312 & 317 & 437 & 500 & 482 & 524 & 593 & 3332 \\
\hline Estudante & 61 & 165 & 182 & 204 & 286 & 241 & 265 & 315 & 1719 \\
\hline Funcionária Pública & 16 & 33 & 32 & 35 & 45 & 49 & 53 & 59 & 322 \\
\hline Lavradora & 10 & 21 & 37 & 61 & 56 & 100 & 110 & 121 & 516 \\
\hline Manicure & 15 & 29 & 31 & 31 & 36 & 52 & 57 & 62 & 313 \\
\hline Pescadora & 9 & 6 & 10 & 8 & 14 & 23 & 25 & 27 & 122 \\
\hline Policiais & 5 & 9 & 10 & 13 & 13 & 13 & 14 & 15 & 92 \\
\hline Outros & 45 & 107 & 106 & 155 & 181 & 223 & 270 & 337 & 1466 \\
\hline Total Geral & 1203 & 2535 & 3101 & 4041 & 4607 & 4885 & 5373 & 6006 & 31793 \\
\hline
\end{tabular}

Fonte: SISP - Sistema Integrado de Segurança Pública; Secretaria Adjunta de Inteligência e Análise Criminal - SEGUP/PA. 
Quanto às atividades desenvolvidas profissionalmente pelas denunciantes de violência doméstica no Estado do Pará de 2008 e 2015, a maior incidência foi de donas de casa e domésticas, totalizando 7.892 casos $(25,1 \%)$, conforme Tabela 5 , acima. Em relação às informações fornecidas quanto à condição de trabalho, $47 \%$ das mulheres desenvolviam algum tipo de trabalho remunerado. Nessa proporção estão incluídas as empregadas no mercado formal, as trabalhadoras informais e as autônomas. As denunciantes eram normalmente mulheres com nível de escolaridade fundamental ou secundária, sendo que as de nível educacional superior totalizaram 656, num universo de 31.793.

Uma pesquisa realizada pelo Data Senado em 2013 mostrou que 34,7\% da população feminina que trabalhava não tinham nenhuma instrução ou possuíam o ensino fundamental incompleto. 30,4\% das mulheres no país não possuíam nenhum tipo de rendimento e 33,7\% sobreviviam com apenas um salário mínimo. Além disso, dentre o percentual de 37,3\% das famílias chefiadas por mulheres, em 21,2\% delas o rendimento provinha do cônjuge (BRASIL, 2013).

Não se atribuiu a violência doméstica como um fato que ocorre somente nas classes sociais de baixa rentabilidade econômica, nem as vítimas apenas como pessoas com baixa escolaridade. No entanto, os números apresentados neste trabalho apontam que a maioria das denúncias provém de vítimas com escolaridade até o ensino fundamental e que, portanto, desenvolvem atividades profissionais de baixa renda. Mesmo atingindo todas as classes sociais, a violência doméstica ainda é predominante nas classes menos favorecidas, sendo as denúncias menos frequentes nas classes média e alta por vergonha ou medo da exposição (OLIVEIRA et al., 2015).

Apesar dos dados estatísticos serem uma importante ferramenta para a produção de indicadores que permitam avaliar a violência contra as mulheres, a menção de dados relacionados às condições socioeconômicas das vítimas é negligenciada, como podemos constatar nas tabelas acima. Essas informações são importantes se considerarmos que o empoderamento econômico é uma das estratégias que defendemos como saída da situação de violência e retomada da vida com maior segurança e tranquilidade.

Como podemos ver na Tabela 6, a seguir, os crimes de ameaça apresentaram um crescimento de 646\% e os de lesão corporal de 403\%. Os crimes de ameaça (9.916 casos), lesão corporal (11.057 casos), agressão (892 casos), injúria (643), dano (373), tentativa de homicídio (129) e difamação (109) foram os mais frequentes, representando 23.115 situações de violência, ou seja, $72,7 \%$ do total. 


\section{TABELA 6}

\begin{tabular}{|c|c|c|c|c|c|c|c|c|c|}
\hline \multicolumn{10}{|c|}{$\begin{array}{l}\text { Demonstrativo da capitulação dos delitos de violência doméstica no Estado do Pará nos anos de } 2008 \text { a } \\
2015\end{array}$} \\
\hline Delitos & 2008 & 2009 & 2010 & 2011 & 2012 & 2013 & 2014 & 2015 & Total Geral \\
\hline Sequestro/Cárcere Privado & 0 & 0 & 0 & 0 & 3 & 0 & 1 & 1 & 5 \\
\hline Tentativa de Agressão & 0 & 0 & 0 & 0 & 1 & 1 & 1 & 2 & 5 \\
\hline $\begin{array}{l}\text { Descumprimento de } \\
\text { Medidas Protetivas }\end{array}$ & 0 & 0 & 0 & 1 & 0 & 1 & 1 & 3 & 6 \\
\hline $\begin{array}{l}\text { Tentativa de Lesão } \\
\text { Corporal }\end{array}$ & 0 & 1 & 0 & 0 & 3 & 0 & 2 & 4 & 10 \\
\hline Apropriação Indébita & 0 & 0 & 0 & 0 & 0 & 3 & 3 & 5 & 11 \\
\hline Cárcere Privado & 4 & 0 & 0 & 0 & 1 & 1 & 3 & 5 & 14 \\
\hline Constrangimento llegal & 3 & 2 & 2 & 2 & 1 & 1 & 2 & 4 & 17 \\
\hline Calúnia & 1 & 3 & 3 & 4 & 3 & 4 & 4 & 4 & 26 \\
\hline Desobediência da Lei & 0 & 4 & 0 & 4 & 4 & 7 & 9 & 11 & 39 \\
\hline Furto & 0 & 1 & 2 & 0 & 9 & 8 & 9 & 10 & 39 \\
\hline Maus Tratos & 5 & 4 & 1 & 6 & 5 & 5 & 6 & 7 & 39 \\
\hline Homicídio & 7 & 0 & 4 & 4 & 3 & 7 & 8 & 9 & 42 \\
\hline Violação de Domicílio & 2 & 7 & 6 & 15 & 9 & 2 & 4 & 4 & 49 \\
\hline Estupro & 3 & 8 & 6 & 17 & 6 & 10 & 13 & 16 & 79 \\
\hline Difamação & 14 & 6 & 21 & 24 & 9 & 10 & 11 & 14 & 109 \\
\hline Tentativa de Homicídio & 6 & 8 & 11 & 24 & 24 & 12 & 28 & 16 & 129 \\
\hline Dano & 8 & 25 & 27 & 74 & 62 & 53 & 59 & 65 & 373 \\
\hline Injúria & 8 & 21 & 44 & 69 & 92 & 103 & 113 & 193 & 643 \\
\hline Agressão Física & 53 & 86 & 112 & 81 & 105 & 139 & 131 & 185 & 892 \\
\hline $\begin{array}{l}\text { Violência Doméstica/Sem } \\
\text { Ident. Capitulação }\end{array}$ & 287 & 572 & 860 & 1190 & 1204 & 1275 & 1402 & 1503 & 8293 \\
\hline Ameaça & 297 & 759 & 926 & 1226 & 1542 & 1543 & 1703 & 1920 & 9916 \\
\hline Lesão Corporal & 507 & 1030 & 1074 & 1320 & 1521 & 1700 & 1860 & 2045 & 11057 \\
\hline Total Geral & 1205 & 2537 & 3099 & 4061 & 4607 & 4885 & 5373 & 6026 & 31793 \\
\hline
\end{tabular}

Fonte: SISP - Sistema Integrado de Segurança Pública; Secretaria Adjunta de Inteligência e Análise Criminal - SEGUP/PA.

De acordo com as informações fornecidas quanto à capitulação de delitos de violência doméstica no Estado do Pará nos anos de 2008 a 2015, pode ser visto na Tabela 6 que 35\% dos casos são de lesão corporal, seguido de ameaça $32 \%$, contra $0,4 \%$ de homicídio, levando em consideração a população feminina do ano de 2010 do Estado, conforme o censo do IBGE de 973.488 .09 habitantes, correspondendo a $51 \%$ da população total do Estado do Pará do mesmo ano (IBGE, 2010).

Um estudo sobre as ocorrências das vítimas de violência doméstica periciadas pelo IML do Alto Vale do Itajaí (SC) nos anos de 2016 e 2017 mostrou a predominância de prevalência da violência física (88,5\%) sobre as outras (11,5\%). Dados esses compatíveis com os encontrados nesta pesquisa (OBERZINER; MEURER; SERAPIÃO, 2019).

Um estudo com informações de casos de violência contra mulheres registrados pela Polícia Civil de Montes Claros (MG), ao analisar as ocorrências e os fatores associados à violência contra a mulher, identificou 7.478 casos de violência contra a mulher, nos quais 79,8\% (5.968) das mulheres se encontravam na fase adulta de suas vidas, sendo que 19,45\% (1.455) foram vítimas de seus próprios companheiros e sofreram 
as mais variadas formas de manifestação da violência, tais como: agressão 32,97\% (480), ameaça 44,49\% (647), estupro 0,48\% (7), injúria 0,27\% (4) e lesão corporal 21,78\% (317) (LEITE et al., 2014).

Das formas de violência elencadas, segundo pesquisa do Data Senado, a mais frequente é a violência física, relatada por $62 \%$ das vítimas, o que faz com que muitas vezes seja esse tipo de dano o foco das campanhas (BRASIL, 2013). As demais formas de violência esbarram em percepções baseadas no senso comum que as tratam como de "menor importância", sendo muitas vezes remetidas a outras esferas de resolução que não o Poder Judiciário, como os atendimentos psicossociais (SOUZA, 2016).

A Central de Atendimento à Mulher, no período de 10 anos (2006 a 2015), realizou 4.708 .978 atendimentos. Desses, 552.748 foram relatos de violência, com destaque para os de violência física $(56,72 \%)$ e violência psicológica (27,74\%). Pode-se constatar que esses dados se assemelham ao do presente estudo quanto aos tipos de violência mais comuns registrados pelas mulheres, sendo: a violência física, estando incluídas aqui a agressão e a lesão corporal, e a violência psicológica, que engloba os vários tipos de ameaça (BRASIL, 2015).

É comum a utilização da ameaça por parte dos seus parceiros íntimos como forma de intimidar as mulheres рага que elas não efetuem a denúncia. Portanto, quando essas mulheres procuram alguma instituição (delegacia de polícia, delegacia da mulher etc.) para efetuar a denúncia, muitas o fazem mais na tentativa de conseguir parar a violência e possibilitar um aconselhamento ao companheiro e, assim, quem sabe, fazê-lo mudar (MOREIRA; BORIS VENÂNCIO, 2011).

A Lei Maria da Penha, em seu art. $7^{\circ}$, destaca que são formas de violência doméstica e familiar contra a mulher, entre outras: a violência psicológica, entendida como qualquer conduta que lhe cause danos emocional e diminuição da autoestima, ou que the prejudique e perturbe o pleno desenvolvimento, ou que vise degradar ou controlar suas ações, seus comportamentos, suas crenças e decisões, mediante ameaça, insulto, chantagem, ridicularizarão, exploração e limitação do direito de ir e vir, ou qualquer outro meio que the cause prejuízo à saúde psicológica e à autodeterminação (SOUZA; BONNA; LEAL, 2018).

Outro importante impacto da violência conjugal física na família é o que se dá sobre a saúde mental dos filhos que a presenciam. Crianças que testemunham violência entre os pais têm maior probabilidade de apresentarem uma série de problemas emocionais e comportamentais, incluindo ansiedade, depressão, baixa autoestima, desobediência, pesadelos e queixas somáticas, além de baixo desempenho escolar (MIRANDA; PAULA; BORDIN, 2010).

Reconhecer os danos causados pela violência em sua complexidade, não só como um problema de justiça e segurança pública, mas também de saúde, é cuidar do indivíduo em sua integralidade, princípio doutrinário e modelo de ação do Sistema Único de Saúde (SUS). A integralidade consiste em um conjunto articulado e contínuo de ações e serviços preventivos e curativos em todos os níveis de assistência (SOUSA; NOGUEIRA; GRADIM, 2013).

A Tabela 7, a seguir, mostra o número de denúncias em que foram instaurados processos nos anos de 2008 a 2015. Quanto ao prosseguimento dos procedimentos instaurados das denunciantes, houve uma redução de 42\% do total de denúncias realizadas no período de 2008 a 2015 em todo o Estado do Pará, segundo informações obtidas do SISP/Web. 


\section{TABELA 7}

\begin{tabular}{|c|c|c|c|c|c|c|c|c|c|}
\hline \multicolumn{10}{|c|}{ Demonstrativo de procedimentos instaurados em delitos configurados de violência doméstica no Estado } \\
\hline Tipos de Procedimentos & 2008 & 2009 & 2010 & 2011 & 2012 & 2013 & 2014 & 2015 & Total Geral \\
\hline Auto de Apreensão & 2 & 1 & 1 & 6 & 5 & 7 & 8 & 9 & 39 \\
\hline Auto de Investigação & 1 & 0 & 1 & 2 & 4 & 5 & 6 & 7 & 26 \\
\hline $\begin{array}{l}\text { Boletim de Ocorrência } \\
\text { Circunstanciado }\end{array}$ & 6 & 3 & 1 & 4 & 5 & 3 & 3 & 4 & 29 \\
\hline Inquérito por Flagrante & 292 & 547 & 637 & 768 & 1124 & 1155 & 1271 & 1398 & 7192 \\
\hline Inquérito por Portaria & 270 & 475 & 545 & 744 & 929 & 887 & 1075 & 1093 & 6018 \\
\hline $\begin{array}{l}\text { Termo Circunstanciado de } \\
\text { Ocorrência }\end{array}$ & 16 & 50 & 34 & 21 & 29 & 19 & 21 & 23 & 213 \\
\hline Total Geral & 587 & 1076 & 1219 & 1545 & 2096 & 2076 & 2384 & 2534 & 13517 \\
\hline
\end{tabular}

Fonte: SISP - Sistema Integrado de Segurança Pública; Secretaria Adjunta de Inteligência e Análise Criminal - SEGUP/PA.

De acordo com Fernandes (2015), muitas mulheres que denunciam os casos de violência doméstica das quais foram vítimas desistem dos processos que apuram a violência, não por conta da inexistência do fato ou da cessação do perigo, mas sim pela mistura de sentimentos como o medo, a insegurança, a vergonha, a desestruturação da base familiar, bem como por questões relacionadas aos fatores econômicos e sociais e às dificuldades no acesso aos órgãos de acesso à justiça.

Um outro item importante que impossibilita o andamento do processo é a falta de provas de materialidade, ou seja, os indícios de autoria do crime. Vários processos não são encaminhados às instâncias adequadas por não terem prova comprobatória do crime de violência doméstica, tais como: laudos, exame de corpo de delito, prontuários médicos e documentos.

A maioria dos processos criminais relacionados à violência doméstica julgados na $4^{a}$ Vara Criminal do Tribunal de Justiça do Estado do Pará possui como desfecho a extinção do processo pela desistência da mulher vítima de violência, a qual, abriria mão da continuidade do processo por motivos diversos relacionados às pressões familiares, retaliações e dependências afetiva/financeira (MAIA, 2019).

\section{GRÁFICO 2}

\section{Procedimentos instaurados em delitos configurados de violência doméstica no Estado do Pará nos anos de} 2008 a 2015

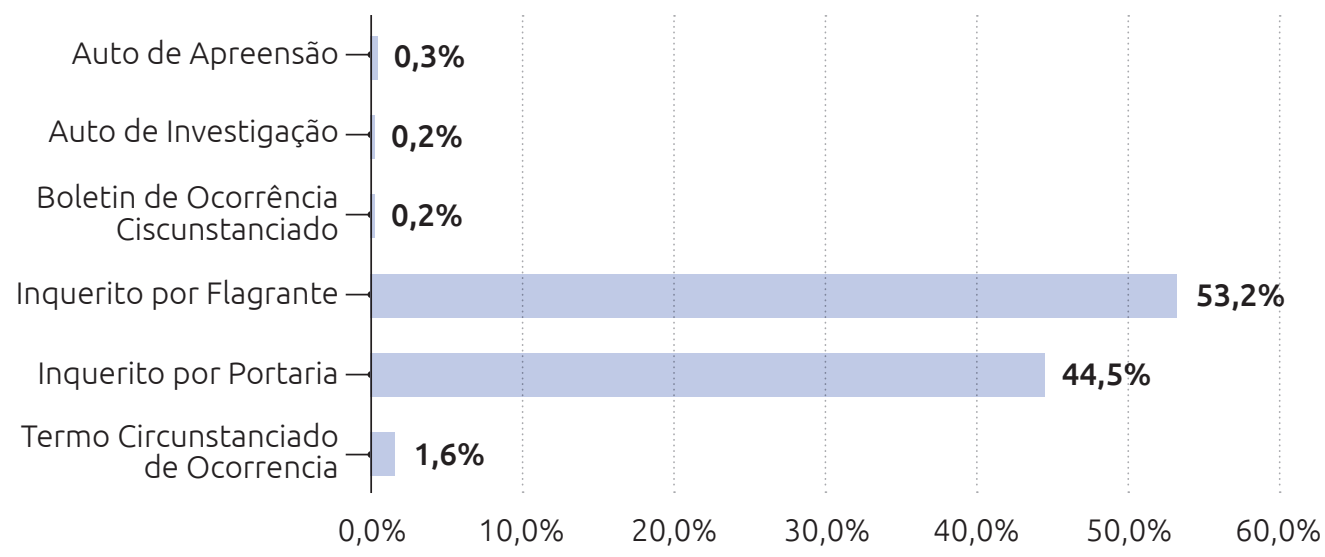


GRÁFICO 3

\section{Quantitativo de crimes contra a mulher enquadrados na Lei Maria da Penha no Estado do Pará nos anos de 2008 a 2015}

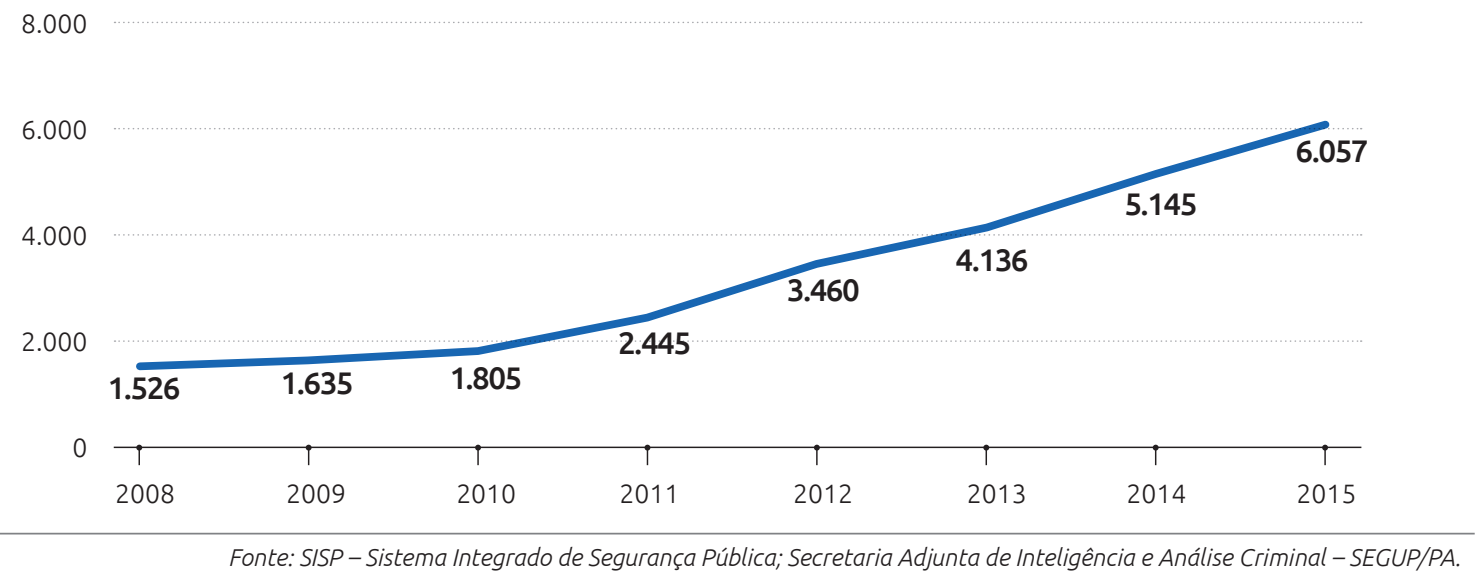

O Gráfico 3 mostra que em 2008 o número de mulheres vítimas de violência doméstica no Estado do Pará era de 1.526, passando a 6.057 em 2015, havendo, portanto, no período, um crescimento da violência doméstica de $296 \%$. Os dados apresentados neste trabalho mostram claramente uma crescente da violência contra a mulher em nosso Estado e, de acordo com o Mapa da Violência, esse fenômeno continua em curva ascendente em nosso país, sendo possível afirmar que as ações governamentais e suas políticas sociais, bem como a Lei Maria da Penha, caminham a passos lentos (WAISELFISZ, 2015).

A pesquisa do Data Senado em 2013 sobre a violência contra a mulher constatou que, por todo o país, 99\% das mulheres já tinham ouvido falar na Lei Maria da Penha, e isso valeu para todos os estratos sociais. Mulheres de todas as idades, níveis de renda e escolaridade, credo ou raça sabiam da existência da Lei criada para coibir a violência doméstica e familiar (BRASIL, 2013). Apesar disso, a pesquisa estimou que mais de 13 milhões e 500 mil mulheres já tinham sofrido algum tipo de agressão (19\% da população feminina com 16 anos ou mais). Dessas mulheres, $31 \%$ ainda conviviam com o agressor. $O$ pior é que das que conviviam com o agressor, 14\% ainda sofriam algum tipo de violência. Esse resultado, quando expandido para a população brasileira, implica dizer que 700 mil brasileiras continuavam sendo alvo de agressões no país (BRASIL, 2013).

Ao focar essa interface, depara-se com amplas implicações ligadas ao fenômeno. A dependência financeira, a proteção e o cuidado com os filhos, bem como o medo da reação do companheiro com a denúncia, são alguns dos motivos que levam a pessoa agredida a permanecer na relação abusiva (PEREIRA, 2017).

Em 2015, o Atlas da Violência Contra a Mulher registrou 4.621 casos de mulheres assassinadas, o maior número em dez anos; em média foram 13 vítimas por dia no Brasil. Os Estados com as maiores taxas de feminicídio naquele mesmo ano foram: Roraima com 10,6\% (quase duas vezes superior à média nacional de 4,7\%), Rio Grande do Norte com 8,3\%, Acre com 8,3\% e Ceará com 8,1\%. Os Estados com menores taxas de feminicídio foram: São Paulo com 2,2\%, Distrito Federal com 2,9\%, Santa Catarina com 3,1\% e Piauí com 3,2\%. Entre as vítimas, 66\% eram negras (CERQUEIRA et al., 2019).

A cultura do patriarcado reafirma a superioridade do homem em detrimento da sujeição da mulher. Nesse contexto, a violência contra a mulher torna-se uma "prática" rotineira, vivenciada por inúmeras mulheres e, portanto, enraizada na sociedade, por isso o enfrentamento é necessário e emergencial (SILVA, 2017). 
Então, tornam-se essenciais ações conjuntas de prevenção, assistência e políticas de garantia dos direitos da mulher por diversos setores envolvidos, tais como: saúde, educação, assistência social, segurança pública, cultura, justiça, entre outros; no sentido de dar conta da complexidade da violência contra as mulheres.

\section{CONCLUSÃO}

De acordo com os dados quantitativos mostrados por este estudo, das 905.694 ocorrências registradas por crimes contra a mulher no Estado do Pará nos anos pesquisados (2008 a 2015), 31.793 (ou seja, 3,5\% do total) foram enquadradas pela autoridade policial como violência doméstica de acordo com a Lei Maria da Penha. A média anual de denúncias foi de 3.974 casos. A maioria das vítimas estava na faixa etária de 18 a 34 anos (61,5\%). Quanto ao grau de escolaridade, 25\% da população estudada possuía ensino fundamental incompleto. Quanto à cor de pele, 75,5\% das mulheres foram registradas como negras. Foi constatado nesta pesquisa que as violências física e psicológica são as mais frequentes, correspondendo, respectivamente, a 35\% e 32\% dos casos. Das queixas registradas, foram instaurados 13.517 inquéritos, o que corresponde a $58 \%$ do total de denúncias. Constatou-se que o crescimento da violência doméstica em nosso Estado nos anos de 2008 a 2015 foi de 296\%.

Apesar dos dados estatísticos serem uma importante ferramenta para a produção de indicadores que permitam avaliar a violência contra as mulheres, a menção de dados relacionados às condições socioeconômicas das vítimas é negligenciada, como podemos constatar neste estudo. Essas informações são importantes se considerarmos que o empoderamento econômico é uma das estratégias que defendemos como saída da situação de violência e retomada da vida com maior segurança e tranquilidade.

Na Lei n 11.340/2006, conhecida como Lei Maria da Penha, a produção de dados pode ser descrita como um quarto eixo de medidas a serem adotadas, juntamente com as medidas de prevenção, proteção e responsabilização em casos de violência doméstica e familiar. Além do incentivo às pesquisas e aos estudos, a Lei traz a recomendação para a criação do Cadastro Nacional de Violência Doméstica e Familiar que deverá disponibilizar dados sobre as ocorrências registradas em todo o país.

Por fim, acredita-se que os dados deste estudo se somam ao campo do conhecimento existente, para evidenciar e/ou desvendar os indicadores de violência contra a mulher e suas formas de enfrentamento, para assim poder confrontar os preconceitos relacionados ao tema, principalmente devido ao desconhecimento e à falta de instrumentalização dos profissionais que lidam com as diferentes facetas ou formas da violência contra a mulher.

\section{REFERÊNCIAS}

ALMEIDA, T. M. C.; PEREIRA, B. C. J. Violência doméstica e familiar contra mulheres negras no Brasil: reflexões pela ótica dos estudos feministas latino-americanos. Crítica e Sociedade: revista de cultura política, v. 2, p. 42-63, 2012.

AUGUSTO, A. O.; LIMA, V. L. A.; SENA, L. X.; SILVA, A. F.; GOMES, V. R.; SANTOS, A. C. B. Mapeamento dos casos de violência contra a mulher na Região Metropolitana de Belém narrados pela mídia impressa do Estado do Pará. Revista Paraense de Medicina, v. 29, p. 22-32, 2015. 
BARRETO, A. C. T. A defensoria pública como instrumento constitucional de defesa dos direitos da mulher em situação de violência doméstica, familiar e intrafamiliar. 242 p. Dissertação (Mestrado em Direito Constitucional). Centro de Ciências Jurídicas, Universidade de Fortaleza, 2007.

BERNARDINO, I. M.; BARBOSA, K. G. N.; NÓBREGA, L. M.; CAVALCANTE, G. M. S; FERREIRA, E. F.; D'AVILA, S. Violência contra mulheres em diferentes estágios do ciclo de vida no Brasil: um estudo exploratório. Revista Brasileira de Epidemiologia, v. 19, p. 740-752, 2016.

BOTELHO, N.; MASSAMI, I.; BRITO, N. B.; FONSECA, S. N. S. da. Perfil das mulheres vítimas de agressão pelo parceiro atendidas no Instituto Médico Legal. Revista Paraense de Medicina, v. 26, p. 17-21, 2012.

BRASIL. Panorama da violência contra as mulheres no Brasil: indicadores nacionais e estaduais. Brasília: Senado Federal; Observatório da Mulher Contra a Violência, 2016.

. Secretaria de Políticas para as Mulheres da Presidência da República. Balanço do Ligue 180. Uma década de conquistas. Brasília, DF, 2015. Disponível em: <http://www.spm.gov.br/assuntos/violencia/ ligue-180-central-de-atendimento-a-mulher/balanco1sem2015-versao-final.pdf>. Acesso em: 1 out. 2015.

Senado Federal. Violência Doméstica e Familiar contra a Mulher. 73 p. Data Senado, Secretaria de Transparência. Brasília, 2013. Disponível em: <http://www.senado.gov.br/senado/datasenado/ DataSenado-Pesquisa Violencia_Domestica_Contra_a_Mulher_2013.pdf>. Acesso em: 6 maio 2016.

. Lei no 11.340, de 7 de agosto de 2006. Disponível em: <http://www.planalto.gov.br/ccivil_03/_ ato2004-2006/2006/lei//11340.htm>. Acesso em: 6 maio 2019.

CACCIAMALI, M. C.; HIRATA, G. I. A Influência da Raça e do Gênero nas Oportunidades de Obtenção de Renda - Uma Análise da Discriminação em Mercados de Trabalho Distintos: Bahia e São Paulo. Estudos Econômicos, São Paulo, v. 35, n. 4, p. 767-795, 2005.

CEPAL. Mulheres afrodescendentes na América Latina e no Caribe: Dívidas de igualdade. (Comissão Econômica para a América Latina e o Caribe). Nações Unidas, 2018.

CERQUeIRA, D.; BUENO, S.; LIMA, R. S.; NEME, C.; FERREIRA, H.; ALVES, P. P.; MARQUES, D.; REIS, M.; CYPRIANO, O.; SOBRAL, I.; PACHECO, D.; LINS, G.; ARMSTRONG, K. C. Atlas da Violência 2019. Brasília: Instituto de Pesquisa Econômica Aplicada, 2019.

FERNANDES, V. D. S. Lei Maria da Penha: O Processo Penal no Caminho da Efetividade. 1. ed. São Paulo: Atlas, v. 1, 2015.

GARCIA, L. P.; DUARTE, E. C.; FREITAS, L. R. S. de; SILVA, G. D. M. da. Violência doméstica e familiar contra a mulher: estudo de casos e controles com vítimas atendidas em serviços de urgência e emergência. Cadernos de Saúde Pública, v. 32, n. 4, e00011415, 2016.

GRANJA, E.; MEDRADO, B. Homens, violência de gênero e atenção integral em saúde. Psicologia e Sociedade, v. 21, p. 25-34, 2009.

IBGE. Censo Demográfico 2010. Pará: IBGE, 2010. Disponível em: <http://censo2010.ibge.gov.br>. Acesso em: 4 mar. 2018.

LEITE, M. T. S.; FIGUEIREDO, M. F. S.; DIAS, O. V.; VIEIRA, M. A.; SOUZA, L. P. S.; MENDES, D. C. Ocorrência de violência contra a mulher nos diferentes ciclos de vida. Rev. Latino-Am. Enfermagem, v. 22, n. 1, p. 85-92, 2014.

MAIA, T. P. Violência doméstica no município de Ananindeua-Pará. 141 p. Dissertação (Mestrado em Segurança Pública) - Instituto de Filosofia e Ciências Humanas, Universidade Federal do Pará, 2019. 
MIRANDA, A. P. C.; COUTINHO, B. H.; MELO, E. M.; RABELO, F. G.; REIS, G. A. C.; FERREIRA, J. C.; CASTRO, L. O.; COSTA, M. F. M.; MORAIS, S. Rede de atenção à mulher em situação de violência no município de Belo Horizonte: uma primeira abordagem. Revista Médica de Minas Gerais, v. 26, p. 286-290, 2016.

MIRANDA, M. P. M.; PAULA, C. S.; BORDIN, I. A. S. Violência conjugal física contra a mulher na vida: prevalência e impacto imediato na saúde, trabalho e família. Revista Panamericana de Salud Pública, v. 27, p. 300-308, 2010.

MORAIS, C. Descrição, análise e interpretação de informação quantitativa. 31 p. Monografia. Escola Superior de Educação, Instituto Politécnico de Bragança, 2015.

MOREIRA, V.; BORIS, G. D. J. B.; VENÂNCIO, N. M. F. O estigma da violência sofrida na relação com seus parceiros íntimos. Psicologia e Sociedade, v. 23, p. 398-406, 2011.

NOGUEIRA, P. L. B.; VENTURA, M. T.; UTIYAMA, M. S. A.; GOMES, H. G. Perfil epidemiológico das mulheres vítimas de violência atendidas no IML de Cuiabá e região. Perspectivas Medicina Legal e Perícias Médicas, v. 4, p. 1-4, 2017.

OBERZINER, D. L.; MEURER, I. M.; SERAPIAO, M. A. Violência doméstica e suas variáveis nos casos atendidos no Instituto Médico Legal da Região do Alto Vale de Itajaí/SC. Perspectivas Medicina Legal e Perícias Médicas, v. 4, n. 1, 2019.

OGG, C. L.; MOREIRA, D.; CAPRI, J.; BILLERBECK, L. M. O.; OLIVEIRA, M. I. A mulher vítima de violência doméstica e familiar em Ponta Grossa: subsídios para o debate. In: $11^{\circ}$ CONEX - Conversando sobre Extensão. Anais... Ponta Grossa, Paraná, UEPG, 2013. Disponível em: <http://www.uepg.br/proex/anais/ trabalhos/11/Comunica\%C3\%A7\%C3\%A30\%200ral/Oral\%20(81).pdf>. Acesso em: 17 nov. 2018.

OLIVEIRA, P. P.; VIEGAS, S. M. F.; SANTOS, W. J.; SILVEIRA, E. A. A.; ELIAS, S. C. Mulheres vítimas de violência doméstica: uma abordagem fenomenológica. Texto \& Contexto Enfermagem, v. 24, n. 1, p. 196-203, 2015.

PEREIRA, N. S. Violência doméstica contra a mulher: do medo à conscientização. 16 p. Bacharelado Interdisciplinar em Ciências Humanas, Universidade Federal de Juiz de Fora, 2017.

SENADO FEDERAL. Painel de Violência Contra Mulheres. 2016. Disponível em: <http://www9.senado. gov.br/QvAJAXZfc/opendoc.htm?document=senado\%2FPainel\%20OMV\%20\%20Viol\%C3\%AAncia\%20 contra\%20Mulheres.qvw\&host=QVS\%40www9\&anonymous=true>. Acesso em: 10 jun. 2019.

SILVA, A. C. G.; OlIVEIRA FILHO, J. S.; SANTOS, K. P. F. dos; BARRETO, A. J. R.; COSTA, C. B. A.; ALMEIDA, S. A. Violência contra mulher: uma realidade imprópria. Revista de Ciências da Saúde Nova Esperança, v. 11 , p. 101-115, 2013

SILVA, L. C. M. Violência Contra a Mulher e Educação: desafios e perspectivas da DEAM/Belém, Pará, Brasil. In: $13^{\circ}$ Mundos de Mulheres \& 11 Fazendo Gênero. Anais... Florianópolis, Santa Catarina, UFSC, 2017.

SÓTER, G.; MAIA, C. Pará registra aumento de 20\% nos casos de feminicídio e mais de 19 mil ocorrências de agressão contra a mulher. 2019. Disponível em: <https://g1.globo.com/pa/para/noticia/2019/03/08/ para-registra-aumento-de-20-nos-casos-de-feminicidio-e-mais-de-19-mil-ocorrencias-de-agressao-contraa-mulher.ghtml>. Acesso em: 15 maio 2020.

SOUSA, A. K. A. de; NOGUEIRA, D. A.; GRADIM, C. V. C. Perfil da violência doméstica e familiar contra a mulher em um município de Minas Gerais, Brasil. Cadernos Saúde Coletiva, v. 21, p. 425-431, 2013. 
SOUZA, L. T. de. Da expectativa à realidade: a aplicação de sanções na Lei Maria da Penha. 416 p. Tese de Doutoramento em Direito, Justiça e Cidadania- Universidade de Coimbra-Portugal, 2016.

; BONNA, A. P.; LEAL, P. T. Reflexões sobre o dano moral em casos de violência doméstica cometida contra a mulher a partir do Recurso Especial n. 1.675.874/MS. Revista de Epidemiologia e Controle de Infecção, v. 1, p. 1-28, 2018.

VALE, S. L. L.; MEDEIROS, C. M. R.; CAVALCANTI, C. O.; JUNQUEIRA, C. C. S.; SOUZA, L. C. Repercussões psicoemocionais da violência doméstica: perfil de mulheres na atenção básica. Revista da Rede de Enfermagem do Nordeste - Rev. Rene, v. 14, p. 683, 2013.

VILARINS, T. Pesquisa revela que quase a metade da população não tem acesso à água potável na Grande Belém. 2019. Disponivel em: <https://www.oliberal.com/pesquisa-revela-que-quase-a-metade-dapopulação-não-tem-acesso-a-água-potável-na-grande-belém-1.124802>. Acesso em: 15 maio 2020.

WAISELFISZ, J. J. Mapa da Violência 2015: Homicídio de mulheres no Brasil. Brasília-DF, 2015. Disponível em: <http://www.mapadaviolencia.org.br/pdf2015/MapaViolencia_2015_mulheres.pdf>. Acesso em: 18 abr. 2018.

WHO. Global and regional estimates of violence against women: prevalence and health effects of intimate partner violence and non-partner sexual violence. World Health Organization, 2013. Disponivel em: <http://apps.who.int/iris/bitstream/10665/85239/1/9789241564625_eng.pdf>. Acesso em: 5 jun. 2019.

ZART, L.; SCORTEGAGnA, S. A. Perfil Sociodemográfico de Mulheres Vítimas de Violência Doméstica e Circunstâncias do Crime. Revista Perspectiva, v. 39, p. 85-93, 2015.
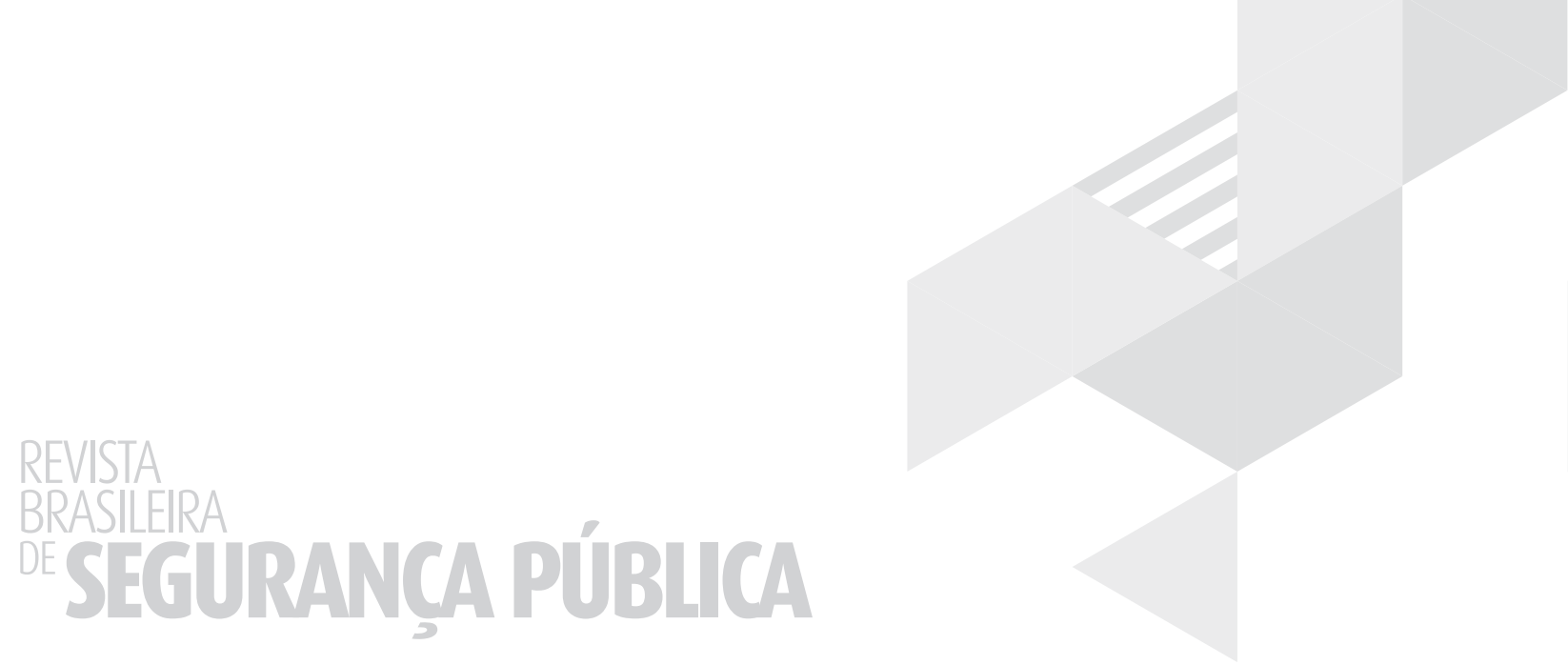